\title{
CENTER OF MASS DEVIATION FROMCENTER OF BASE OF SUPPORT AS A MEASURE OF FRONTAL AND SAGITTAL STABILITY
}

\author{
Mohammed Alamoudi, M.S., Damon Stambolian, M.S., and ShihabAsfour, Ph.D \\ Department of Industrial Engineering, University of Miami, \\ 1251 Memorial Dr, Coral Gables, FL 33146, USA.
}

\begin{abstract}
Fall incidents remain a major issue for workers in the construction and industrial sites. From biomechanical perspectives the majority of falls occurredwhen the body'scenter of mass (CoM) leaves the base of support (BoS). Several measuresquantify stability based on the trajectories of the CoM, such as excursion, sway length, and mean displacement velocity. Nonetheless, none of these measures evaluate stability based on the optimal location of stability, which is the center of base of support (CBoS). Therefore, the main goal of this paper is to introduce new measures that evaluate stability by determining the deviation of the CoM from the CBoSin the Anterior-Posterior and Medio-Lateral directions. A lifting experiment was conducted to comparethe new measures with the existing stability measures. Participants lifted a box with different weights and placed it on a shelf with different heights. The trajectories of the CoM were captured through motion capturing system. The statistical analysis showed that the weight, height, and the interaction had statically significant effect on body stability. While comparing the intraclass correlation (ICC) values for each stability measure, (i.e. a measure of reliability), the proposed measures proved to be more reliable (i.e. highest ICC) than the existing stabilitymeasures. The high ICC values of the proposed stability measures, as compared to the existing stability measures, are a clear indication of their superior reliability. Moreover, the data indicated that increasing the load and the height resulted in an increaseofinstability.
\end{abstract}

\section{KEY WORDS}

Biomechanics; Center of base of support (CBoS); Center of mass (CoM); Deviation; Stability.

\section{INTRODUCTION}

Falls in the workplace are major causes of fatalities and injuries incidents. Falls from elevation were reported to be the second leading cause of death in industrial and construction sites, second only to transportation [1]. In 2013, it took the lives of 699 workers while they were doing their normal job [1]. Moreover, $44 \%$ of the total fatal falls occurred in the construction sites, where the workers were performing their normal job activities, such as handling materials or equipment, and walking from a working area to another [1]. It has been suggested that loss of balance is the main reason of occupational falls. Therefore, the causes of loss of balance in the working places should be inspected in order to minimize the number of fatalities and injuries. 
Three factors affect the control of postural stability. Namely, environmental, task-related, and personal factors [2]. Environmental factors involve the information available from visual interaction, such as moving visual scenes, depth perception, and physical interactions, such as restricted area, and material properties of support surfaces. Task-related factors include load handling, physical exertion, fatigue, and complexity of tasks. Personal factors include individual differences, work experience, and interaction with personal protective equipment.

One of several issues that affects postural stability is manual material handling tasks. Therefore, investigating and studying the ergonomics and biomechanics aspects of these tasks are important in orderto minimize injuries and fatalities that are caused by loss of balance. In the construction and industrial fields there are different tasks that require frequent lifting, holding and carrying loads with different body postures. Loads lifting changes the configuration masses, requires muscles activity and thus directly affect balance. In addition ,holding a heavy load results in increased sway magnitude. The additional task of controlling an external load appears to make stability recovery more difficult [3]. Schiffman [4]investigated the effects of load carried by soldiers upon postural sway, and found that increasing load weight increased postural sway and required the load carriers to exert control of the load in order to maintain balance. Based on theoretical considerations, Davis [5]found that loads decrease postural stability when held at or above the waist level. Therefore, the Heavier the load, the more effect will be on body stability. According to Holbein [6] who investigated the effect of carrying a load with one hand and two hands, asymmetric carrying was found to be more unstable than symmetric carrying.

The risk parameters of falls may include worker's task and posture, such as bending or squatting, and availability of personal protective equipment and barriers [7]. According to Parsons [8], falls occurred while workers were walking forwards or backwards $36 \%$, standing $18 \%$, kneeling $21 \%$, climbing $7 \%$ and handling materials $14 \%$. Standing after maintaining working postures may result in instability and could cause a fall. Therefore, DiDomenico [9] assessed the magnitude of this imbalance, and concluded that bending over at waist caused the smallest changes in stability measures, whereas the reclined kneeling posture resulted in the largest. Additionally, DiDomenico [10]surveyed construction workers to find which postures resulted in less stability. The most common non-erect postures, such as bent at waist, squatting, and kneeling were reported to produce threat to stability.

The maintenance of stability is the responsibility of the postural control system, which consists of sensory, nervous, and motor systems [11]. Sensory system delivers information regarding the position of body segments in relation to other segments and to the environment. Central nervous system receives the information delivered by the sensory system, and then sends nervous impulses to the muscles (i.e. motor system) to assure that the vertical projection of the body's center of mass (CoM) remains within the base of support (BoS) [11]. External forces, such as gravitational force, and internal forces, such as heartbeat and breathing, are acting continuously on the human body even when the body is in static condition. All these forces affect the CoM continuously. Therefore, the human body is never in a condition of perfect equilibrium (i.e. the body is continuously swaying).

The classical definition of the postural stability is based upon the global CoM position and its displacement within the base of support [12]. Therefore, the movement of the CoM is the variable that actually causes the sway of the whole body. The components in the Anterior-Posterior $(\mathrm{A} / \mathrm{P})$ and Medio-Lateral (M/L) directions are the components of interest in studying postural stability. Several measures are used to measure body sway from of the CoMtrajectories. Some of the 
measures are computed separately for each direction (i.e. the $\mathrm{A} / \mathrm{P}$ or $\mathrm{M} / \mathrm{L}$ ), such as the excursion of the CoM, and sway velocity. Moreover, other measures are computed in both directions simultaneously, such as the average sway length, and mean displacement velocity. These measures have been widely used in occupational safety research $[13,14,15,16$, and 17]. The major drawback of postural stability measures is lack of reliable and sensitive sway measures that could be used for the evaluation of postural stability [18].

None of the existingmeasures are computed based on a reference point where the optimal stability concentrates. Therefore, this study aims to introduce new measures that measure stability based on the deviation of CoM from a reference point. The reference point, which has the best stability, will be the center of the subject's base of support $(\mathrm{CBoS})$. Moreover, the new measures will be compared with the other stability measures in order to check its reliability by conducting an experiment and observe its intraclass correlation coefficient (ICC) values, which is a measure of reliability. Each subject were asked to lift a box with three different weights, and place it on a shelf with two different heights. This experiment was selected, because there has been less focus on the task-related factors (i.e. manual material handling) that affect body stability. It was expected that the proposed measureswillmeasurestability more precisely than the existing stability measures. Moreover, it was expected that heavier load will decrease stability, and lowering the working surface that force the subject to change his/ her normal posture will increase sway.

\section{STABILITY MEASURES}

\subsection{EXISTING MEASURES}

There are several measures that are commonly used in stability studies. Namely, excursion of CoM, which is the distance between the maximum and minimum CoM displacement in the $\mathrm{A} / \mathrm{P}$ (eq. 1), and M/L directions (eq. 2). Moreover, CoM velocity, which determines how fast the CoM is moving in the A/P (eq. 3), and M/L directions (eq. 4). Additionally, average sway length, which is the average distance traveled by the CoM in both directions (eq. 5). In addition, mean displacement velocity, which is the displacement of the CoM in both direction per unit time (eq. 6). These measures have been widely used in occupational safety research $[13,14,15,16$, and 17].

The equations are as follow.

$$
\begin{gathered}
\text { A/P Excursion }(\mathrm{mm})=\left|y_{\max }-y_{\min }\right| \ldots \text { eq. } 1 \\
\text { M/L Excursion }(\mathrm{mm})=\left|x_{\max }-x_{\min }\right| \ldots \text { eq. } 2 \\
\text { A/P Velocity }(\mathrm{mm} / \mathrm{sec})=\frac{1}{T} \sum_{i=1}^{N}\left|y_{i}-y_{i-1}\right| \ldots \text { eq. } 3 \\
\text { M/L Velocity }(\mathrm{mm} / \mathrm{sec})=\frac{1}{T} \sum_{i=1}^{N}\left|x_{i}-x_{i-1}\right| \ldots \text { eq. } 4 \\
\text { Average Sway Length }(\mathrm{mm})=\frac{\sum_{i=1}^{N} \sqrt{\left(x_{i}-x_{i-1}\right)^{2}+\left(y_{i}-y_{i-1}\right)^{2}}}{N} \ldots \text { eq. } 5 \\
\text { Mean Displacement Velocity }(\mathrm{mm} / \mathrm{sec})=\frac{\sum_{i=1}^{N} \frac{\sqrt{\left(x_{i}-x_{i-1}\right)^{2}+\left(y_{i}-y_{i-1}\right)^{2}}}{t_{i}-t_{i-1}}}{N} \ldots \text { eq. } 6
\end{gathered}
$$


Where,

$y_{\max }:$ Maximum position of $\mathrm{CoM}$ in the $\mathrm{y}$-axis

$y_{\min }$ : Minimum position of CoM in the $\mathrm{y}$-axis

$x_{\text {max }}$ : Maximum position of $\mathrm{CoM}$ in the $\mathrm{x}$-axis

$y_{i}$ : Location of CoM in the $\mathrm{y}$-axis at frame $i$

$x_{i}$ : Location of CoM in the $\mathrm{x}$-axis at frame $i$

$T$ : Total time of the trial

$t_{i}$ : Time at frame $i$

$N$ : Number of frames

\subsection{Proposed Measures: Deviation Of Com From Cbos}

Based on our knowledge, none of the existingstability measures that are commonly used in stability research evaluate stability based on a point in the BoS that has the least sway. Therefore, the main goal of this paper is to introduce new stability measures that measure stability based on a point where the optimal stability locates. When the CoM of a human body lies at or near the $\mathrm{CBoS}$, it is more stable than when it lies far from it or near the edge of the BoS[19]. Therefore, the $\mathrm{CBoS}$ is considered the reference point where the optimal stability is. Three new measures calculate stability by measuring the deviation or the distance from the CoM to the $\mathrm{CBoS}$, as shown below. Equation 7 measures stability by finding the absolute value of the difference between the location of the $\mathrm{CoM}$ to the $\mathrm{CBoS}$ in the $\mathrm{A} / \mathrm{P}$ (or fore-aft) direction. Equation 8 does the same but in the $\mathrm{M} / \mathrm{L}$ (or sideways) direction. Equation 9 measures the actual distance between the CoM and the CBoS by calculating the square root of the summation of the deviation in each directions squared. The equations are as follow.

$$
\begin{aligned}
A / P \operatorname{Dev}_{i}(m m) & =\left|\operatorname{CBoS}_{A P_{i}}-\operatorname{CoM}_{A P_{i}}\right| \ldots \text { eq. } 7 \\
M / L \operatorname{Dev}_{i}(m m) & =\left|\operatorname{CBoS}_{M L_{i}}-\operatorname{CoM}_{M L_{i}}\right| \ldots \text { eq. } 8 \\
\operatorname{ResultantDev}_{i}(\mathrm{~mm}) & =\sqrt{A / P \operatorname{Dev}_{i}^{2}+M / L \operatorname{Dev}_{i}^{2}} \ldots \text { eq. } 9
\end{aligned}
$$

Where,

$A / P \operatorname{Dev}_{i}$ : The deviation of the CoM from $\mathrm{CBoS}$ in the fore-aft direction at frame $i$

$C_{B O S} S_{A P_{i}}$ : The component of the $\mathrm{CBoS}$ in the fore-aft direction at frame $i$

$\operatorname{CoM}_{A P_{i}}$ : The component of the CoM in the fore-aft direction at frame $i$

$M / L D e v_{i}$ : The deviation of the CoM from CBoS in the sideways direction at frame $i$

$C_{B O S} S_{M L_{i}}$ : The component of the $\mathrm{CBoS}$ in the sideways direction at frame $i$

$\operatorname{CoM}_{M L_{i}}$ : The component of the CoM in the sideways direction at frame $i$

ResultantDev $v_{i}$ : The resultant deviation of the CoM from the CBoS at frame $i$

The previous formulas measure stability at each frame. Therefore, at the end of a trial of an experiment, these values should be averaged by dividing it by the number of frames in order to get a value that represents the stability for that trial. The graphical illustration of the proposed equation is shown in Figure 1. The most important part in the previous equations is to find the location of the $\mathrm{CBoS}$ accurately. A brief explanation about finding the location of the $\mathrm{CBoS}$ will be found in the appendix. 


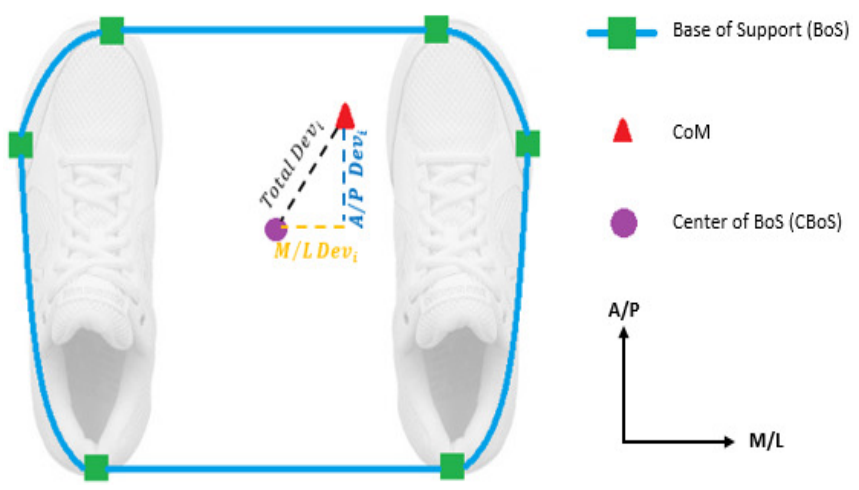

Figure1. Proposed stability measures.

\section{METHODOLOGY}

\subsection{PARTICIPANTS}

Eight male participants were recruited from University of Miami. They were well educated and informed about the purpose of the study and the activity they would perform during the experiment. All participants were male subjects, since most of the workers in the industrial and construction sites who perform lifting tasks are males. All participants were in good health conditions, and they neither had self-reported injuries, nor musculoskeletal disorders within the previous 12 months. The experiment was approved by the University of Miami's Institutional Review Board (IRB), and each participant completed an informed consent before conducting the experiments. Table 1 shows the demographics information.

Table 1. Demographics Information.

\begin{tabular}{|c|c|c|c|}
\hline Sample Size & Age (year) & Height $(\mathbf{c m})$ & Body Mass $(\mathbf{k g})$ \\
\hline 8 & $27.15 \pm 3.98$ & $172.92 \pm 6.46$ & $83.2 \pm 8.78$ \\
\hline
\end{tabular}

\subsection{EXPERIMENTAL DESIGN}

The study used a full factorial design with two independent variables. Namely, shelf height, and load weight. The levels will be described in the independent variables section. The height of the shelf, and the weight of the load were selected based on a previous experiment that simulated precision placement of an avionics box on shelves [20]. Each participant received the same six weight/ height treatment conditions.

\subsection{EQUIPMENT AND TOOLS}

A plywood shelf was constructed with an adjustable height. The shelf height could be changed from30" to50". Moreover, three different boxes were used each with different weights. Kinematic data were captured and recorded at the Biomechanics laboratory at the University of Miami with the Vicon Motion Capturing System (Oxford Metrics, United Kingdom) Nexus software 
International Journal of Biomedical Engineering and Science (IJBES), Vol. 3, No. 1, January 2016

version1.6.1.57351 and 10 MX cameras with a resolution of 1024 x 1024 pixel, and sampling rate $120 \mathrm{~Hz}$. Moreover, a special VBA code was written to calculate the proposed stability measures. The code calculates other stability measures, such as excursion of CoM in each direction, the displacement velocity in each direction, average sway length, and the mean displacement velocity. Furthermore, the code provides several charts that illustrate the deviation of CoM from the center of BoS. A brief explanation of the code will found in the appendix section.

\subsection{INDEPENDENT VARIABLES}

Two factors were selected as the independent variables in the study, and each one consisted of multiple levels. First, the height of the shelf, which had two levels 30" and 50". The first level will show the effect of squatting while carrying load on stability measures. The subject was instructed not to stoop while placing the load, because squatting will provide more stability than stooping. The second level will show the effect of standing erectly while lifting a weight on stability measures. It was expected that squatting produce less stability than standing normally. The second factor was the mass of the load that would be carried and placed on the shelf. It had three levels 25lb., 35lb., and 45lb. These weights were selected based on an experiment that was conducted to study the muscle activity of accurate placing of avionics boxes [20]. It was expected that lifting heavy weight will generate more sway.

\subsection{DEPENDENT VARIABLES}

Vicon Nexus Motion Capturing System with its 10 cameras were used to find the trajectories of CoM.Ninestability measures were the dependent variables in this study. The first three measures were the proposed ones. Namely, the average deviation of CoM from the CBoS in the A/P, M/L separately, and the resultant deviation in both direction together. The other six measures were excursion of CoM, the displacement velocity in each direction, average sway length, and the mean displacement velocity. These measures were selected because they are the most common measures that are used in stability studies. These measures have been widely used in occupational safety research $[13,14,15,16$, and 17]. Later on, the proposed measures will be compared with the existing measures to check its reliability.

\subsection{Experimental Protocol}

In the beginning, each subject performed two practice lifts for training purpose. Then, 39 reflective markers were attached to subject's body in order to capture and record the data through the 10 cameras, as shown in Figure 2. Participants were randomly assigned to each condition of the experiment. For the 50" height, the subject carried the load and stood on front of the shelf, and the data collection started. For the 30" height, the subject carried the load and stood on front of the shelf and then he squatted. Thenthe data collection started. Later, the subject started to place the load on the shelf. After placing the box and before deforming the BoS, the data collection was stopped.Although Lafond [21] observed that two trials were enough to obtain reliable measures of postural stability, and at least two measurements are required to investigate its reliability [22], each subject performed three trials for each condition of the experiment, in order to increase the accuracy in the reliability calculation. 
International Journal of Biomedical Engineering and Science (IJBES), Vol. 3, No. 1, January 2016
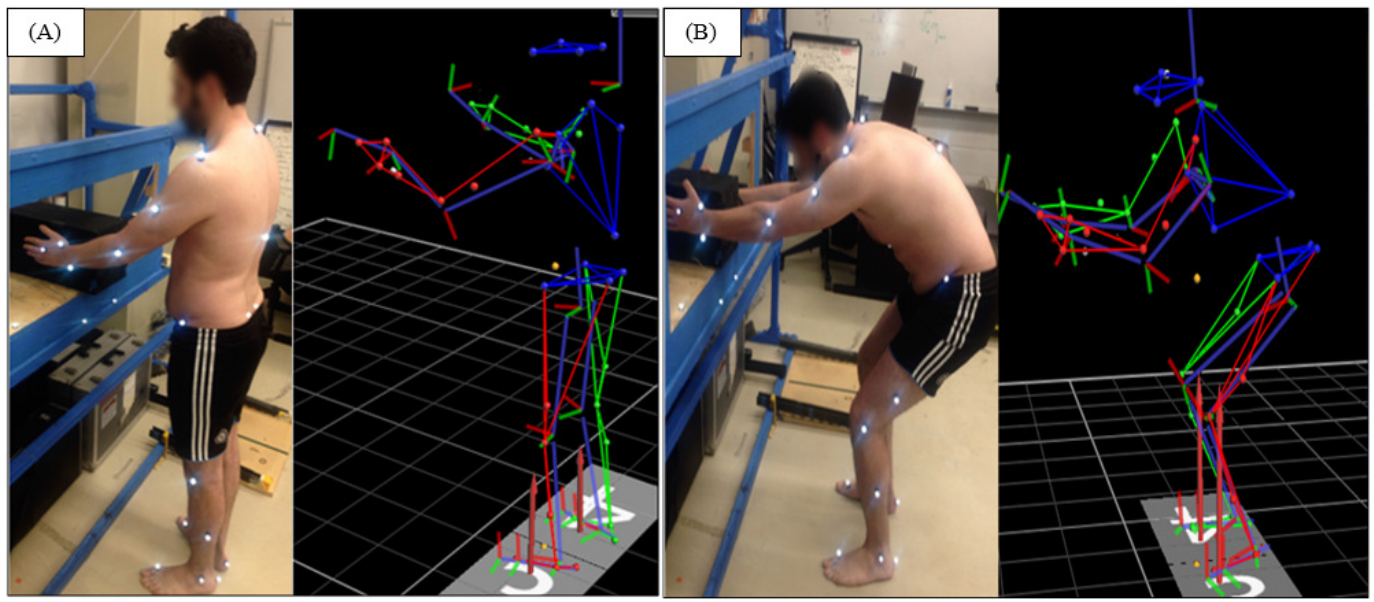

Figure 2.The 39 reflective markers that were attached to each subject.The markers were captured and recorded through motion capturing system to generate the stick figure. (A) Shows the trial of placing the box on 50" shelf height. (B) Shows the trial of placing the box on 30" shelf height.

\section{RESULTS}

Each stability measure was calculated for each of the six weight/ height treatment conditions. Mean and standard deviation values of each parameter are shown Table 2. The statistical significance of each parameter is shown in Table3.

Table 2. Mean and standard deviation of each stability measure for different weight/ height treatment conditions.

\begin{tabular}{|c|c|c|c|c|c|c|c|c|}
\hline \multirow{2}{*}{\multicolumn{3}{|c|}{$\begin{array}{c}\text { Height (") } \\
\text { Weight (lb.) }\end{array}$}} & \multicolumn{3}{|c|}{30} & \multicolumn{3}{|c|}{50} \\
\hline & & & 25 & 35 & 45 & 25 & 35 & 45 \\
\hline \multirow{6}{*}{ 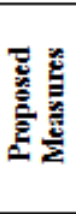 } & \multirow{2}{*}{ Average M/L Deviation (mm) } & Mean & 22.01 & 29.37 & 22.27 & 18.33 & 20.14 & 23.19 \\
\hline & & S.D. & 5.23 & 8.93 & 3.37 & 3.81 & 3.13 & 4.08 \\
\hline & \multirow{2}{*}{ Average A/P Deviation (mm) } & Mean & 90.81 & 101.02 & 104.76 & 44.10 & 39.6 & 59.46 \\
\hline & & S.D. & 10.24 & 6.09 & 6.33 & 6.15 & 8.35 & 9.62 \\
\hline & \multirow{2}{*}{ Total Deviation (mm) } & Mean & 94.74 & 120.09 & 110.22 & 44.42 & 50.57 & 95.0 \\
\hline & & S.D. & 10.235 & 22.103 & 12.22 & 10.51 & 11.5 & 15.14 \\
\hline \multirow{12}{*}{ 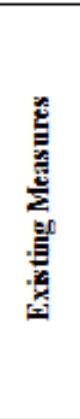 } & \multirow{2}{*}{ M/L Excursion (mm) } & Mean & 43.67 & 98.47 & 90.07 & 50.06 & 43.65 & 51.72 \\
\hline & & S.D. & 7.73 & 11.83 & 8.96 & 12.12 & 8.79 & 5.62 \\
\hline & \multirow{2}{*}{ A/P Excursion (mm) } & Mean & 177.4 & 181.95 & 120 & 100.14 & 107.63 & 111.68 \\
\hline & & S.D. & 25.28 & 6.32 & 6.85 & 7.31 & 6.88 & 10.8 \\
\hline & \multirow{2}{*}{$\mathrm{M} / \mathrm{L}$ Velocity $(\mathrm{mm} / \mathrm{sec})$} & Mean & 2.91 & 3.54 & 4.67 & 2.01 & 3.57 & 3.85 \\
\hline & & S.D. & 1.64 & 0.79 & 1.57 & 2.83 & 0.67 & 0.79 \\
\hline & \multirow{2}{*}{ A/P Velocity $(\mathrm{mm} / \mathrm{sec})$} & Mean & 11.05 & 11.23 & 10.99 & 9.85 & 7.82 & 8.94 \\
\hline & & S.D. & 5.35 & 2.8 & 1.54 & 1.75 & 1.65 & 1.22 \\
\hline & \multirow{2}{*}{$\begin{array}{l}\text { Mean Displacement Velocity } \\
(\mathrm{mm} / \mathrm{sec})\end{array}$} & Mean & 11.44 & 12.26 & 9.5 & 10.6 & 9.57 & 12.16 \\
\hline & & S.D. & 1.64 & 1.69 & 1.76 & 1.14 & 1.75 & 1.71 \\
\hline & \multirow{2}{*}{ Average Sway Length (mm) } & Mean & 0.74 & 0.84 & 0.78 & 0.64 & 0.59 & 0.81 \\
\hline & & S.D. & 0.18 & 0.11 & 0.12 & 0.12 & 0.1 & 0.08 \\
\hline
\end{tabular}


International Journal of Biomedical Engineering and Science (IJBES), Vol. 3, No. 1, January 2016

\subsection{HEIGHT}

From the two-way repeated measures ANOVA for each stability measure, it was obvious that the height factor had highly significant impact on all dependent variables $(\mathrm{p}<0.01)$, as seen in Table 3. Moreover, the shelf height of 30" produced less stability than the 50" height, because thesubject was squatting in the first condition, which produces more stress on muscles than the second condition [20]. Therefore, when the height of the working surface is lowered, body stability decreases, as shown in the Figure3.

\subsection{WEIGHT}

As shown in Table 3, the weight factor had a significant effect on all stability measures $(\mathrm{p}<$ 0.0.05), except the A/P velocity. According to Bhattacharya [15], an effect on all or any stability measure implies an increase in postural sway or instability, because under ideal conditions of upright postural stability, a person would produce minimal sway, whereas poor postural stability would result in a significant increase of most sway measures, such as sway velocity, and CoM excursion $[23,24]$. Therefore, the weight factor has a significant impact on body sway. Moreover, since there are three different levels in the weight variable (i.e. 25, 35, and $45 \mathrm{lb}$.), Tukey's posthoc analysis was used to check the significant difference between the levels. The tests showed that there was a significant difference between $25 \mathrm{lb}$. and $45 \mathrm{lb}$. $(\mathrm{p}<0.001)$. Nevertheless, there was no significant difference when the load was $35 \mathrm{lb}$. and the other weights. Therefore, when the lifted weight increases, body stability decreases, as shown in Figure 3.

\subsection{INTERACTION OF HEIGHT AND WEIGHT}

According to the repeated measures ANOVA, the interaction effect of height and weight factors was highly significant on all stability measures $(\mathrm{p}<0.01)$ except the A/P velocity, as shown in Table 3. Therefore, increasing the load being carried with non-erect posture produces more instability. Based on our knowledge, none of the previous studies investigate the effect of taskrelated factor (i.e. manual material handling) on postural stability.

Table 3. Summary of statistical results (p-value) for the effect of load placing at different heights on several measures of stability. (-) $\mathrm{p} \geq 0.05 ;(+) 0.05>\mathrm{p} \geq 0.01 ;(++) 0.01>\mathrm{p} \geq 0.001 ;(+++) \mathrm{p}<0.001$.

\begin{tabular}{|c|c|c|c|c|}
\cline { 2 - 5 } \multicolumn{1}{c|}{} & Stability Measure & Weight $(\mathbf{W})$ & Height $(\mathbf{H})$ & W X A \\
\hline \multirow{2}{*}{\multicolumn{2}{c|}{ Average M/L Deviation }} & ++ & +++ & +++ \\
\cline { 2 - 5 } & Average A/P Deviation & ++ & +++ & +++ \\
\cline { 2 - 5 } & Total Deviation & +++ & +++ & +++ \\
\cline { 2 - 5 } & M/L Excursion & +++ & +++ & ++ \\
\cline { 2 - 5 } & A/P Excursion & +++ & +++ & ++ \\
\cline { 2 - 5 } & M/L Velocity & +++ & ++ & + \\
\cline { 2 - 5 } & A/P Velocity & - & +++ & +++ \\
\cline { 2 - 5 } & Mean Displacement Velocity & + & ++ & ++ \\
\cline { 2 - 5 } & Average Sway Length & +++ & ++ & + \\
\hline
\end{tabular}


International Journal of Biomedical Engineering and Science (IJBES), Vol. 3, No. 1, January 2016

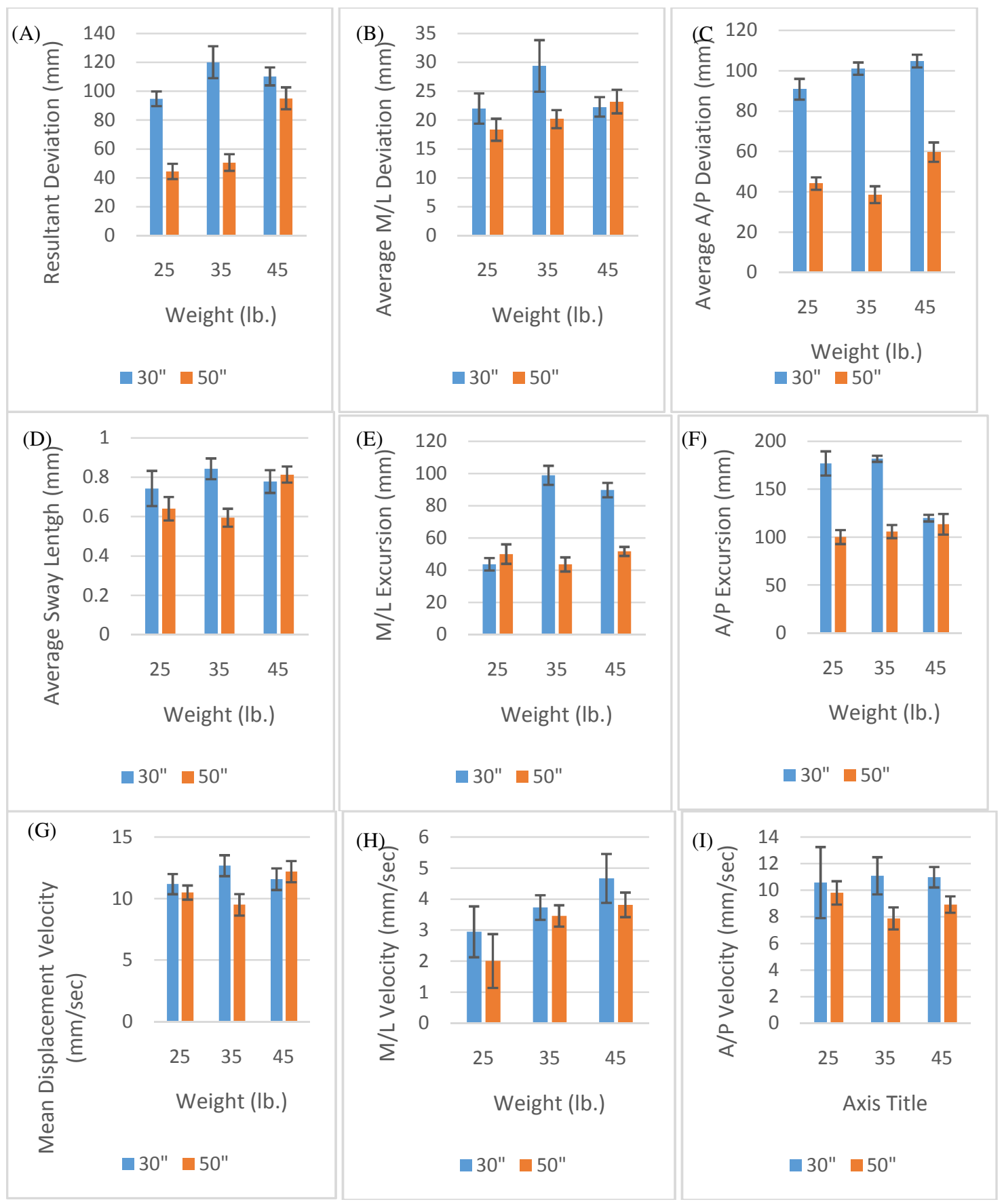

Figure 3.Means with 2 standard error range of the proposed measures: (A) Resultant deviation, (B) M/L deviation, (C) A/P deviation, and the existing measures (D) average sway length, (E) M/L excursion, (E) A/P excursion, (G) mean displacement velocity, (H) M/L velocity, (I) A/P velocity . Obviously, lowering the working surfaces, decreased body stability. Additionally, heavy loads increased instability. 


\subsection{Reliability of the Proposed Stability Measures}

Measurements are almost always exposed to various types of errors, which cause the measured value to differ in each trial of an experiment. If reliability is high, measurement errors are small in comparison to the true differences between subjects. The parameter that is used to assess reliability is called intraclass correlation coefficient (ICC). It takes the values between zero and one, with a value close to one corresponding to small amount of variability, and a value close to zero corresponding to large amount of variability due to error. According to Bartlett [25], in comparing between different measures, using the one with higher reliability (i.e. higher ICC) will give greater statistical power to find differences between groups. Reliability is a useful tool to compare different measurements methods. Reliability refers to the extent by which the measurement is inherently reproducible, or the degree to which the measurement influenced by measurement errors [26, 27]. An advantages of using reliability of measures is that it can be used to compare them even if they were given in different scales, as the ICC is dimensionless [25]. Therefore, the reliability of the proposed measures will be compared to other stability measurements in order to check its reliability and accuracy of capturing stability.

In order to compare the reliability of each stability measure, ICC values were calculated between the three replications of each weight/ height treatment condition. As described earlier that the resultant deviation measures stability in both directions (i.e. A/P, and M/L) together, its ICC should be compared with the measures that evaluate stability in both directions, such as mean displacement velocity, and average sway length. Among all the three measures, the most reliable one was the resultant deviation which had the highest ICC, as shown in Table 4 and Figure 4 (a). Moreover, the average A/P deviation should be compared with the A/P excursion, and A/P velocity. Again the proposed measure showed more reliability than the other, as shown in Figure 4 (b). Same conclusion was drawn with the average M/L deviation when it was compared with $\mathrm{M} / \mathrm{L}$ excursion, and M/L velocity, as shown in Figure 4 (c). Another indication of reliability of the proposed measures can observed from the narrow $95 \%$ confidence interval of its ICC value, as shown in Table 4.

Table 4.Intraclass correlation coefficient (ICC) values with its 95\% CI for each stability measure. Where the lower bound of the CI was negative, it was truncated to 0 , since ICC value can be from 0 to 1.

\begin{tabular}{|c|c|c|c|c|c|c|c|c|}
\hline \multirow{2}{*}{\multicolumn{3}{|c|}{$\begin{array}{c}\text { Height (cm) } \\
\text { Weight (N) }\end{array}$}} & \multicolumn{3}{|c|}{30} & \multicolumn{3}{|c|}{50} \\
\hline & & & 25 & 35 & 45 & 25 & 35 & 45 \\
\hline \multirow{6}{*}{ 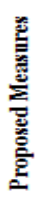 } & \multirow{2}{*}{ Average $A / P$ Deviation } & ICC & 0.92 & 0.87 & 0.91 & 0.91 & 0.93 & 0.89 \\
\hline & & $95 \% \mathrm{CI}$ & $0.61-0.98$ & $0.4-0.97$ & $0.64-0.98$ & $0.54-0.98$ & $0.7-0.97$ & $0.5-0.98$ \\
\hline & \multirow{2}{*}{ Average $M / L$ Deviation } & ICC & 0.79 & 0.83 & 0.89 & 0.80 & 0.81 & 0.85 \\
\hline & & $95 \% \mathrm{CI}$ & $0.4-0.95$ & $0.4-0.96$ & $0.5-0.97$ & $0.3-0.96$ & $0.4-0.96$ & $0.42-0.97$ \\
\hline & \multirow{2}{*}{ Total Deviation } & ICC & 0.96 & 0.93 & 0.91 & 0.93 & 0.93 & 0.94 \\
\hline & & $95 \% \mathrm{CI}$ & $0.8-0.98$ & $0.63-0.97$ & $0.51-0.98$ & $0.7-0.96$ & $0.63-0.97$ & $0.7-0.99$ \\
\hline \multirow{12}{*}{ 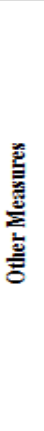 } & \multirow{2}{*}{ M/L Excursion } & ICC & 0.46 & 0.32 & 0.20 & 0.55 & 0.50 & 0.40 \\
\hline & & $95 \% \mathrm{CI}$ & $0.1-0.77$ & $0-0.69$ & $0-0.71$ & $0-0.73$ & $0-0.71$ & $0-0.79$ \\
\hline & \multirow{2}{*}{ A/P Excursion } & ICC & 0.52 & 0.40 & 0.60 & 0.40 & 0.50 & 0.33 \\
\hline & & $95 \% \mathrm{CI}$ & $0-0.9$ & $0-0.8$ & $0-0.9$ & $0-0.8$ & $0-0.9$ & $0-0.86$ \\
\hline & \multirow{2}{*}{ M/L Velocity } & ICC & 0.63 & 0.67 & 0.74 & 0.71 & 0.69 & 0.68 \\
\hline & & $95 \% \mathrm{CI}$ & $0-0.9$ & $0-0.81$ & $0-0.77$ & $0-0.75$ & $0-0.82$ & $0-0.84$ \\
\hline & \multirow{2}{*}{ A/P Velocity } & ICC & 0.87 & 0.76 & 0.85 & 0.79 & 0.70 & 0.62 \\
\hline & & $95 \% \mathrm{CI}$ & $0.01-0.97$ & $0.01-0.83$ & $0.03-0.9$ & $0.02-0.86$ & $0-0.83$ & $0.02-0.92$ \\
\hline & \multirow{2}{*}{ Mean Displacement Velocity } & ICC & 0.82 & 0.85 & 0.88 & 0.81 & 0.81 & 0.84 \\
\hline & & $95 \% \mathrm{CI}$ & $0.35-0.9$ & $0.2-0.9$ & $0.5-0.9$ & $0.25-0.95$ & $0.16-0.96$ & $0.14-0.97$ \\
\hline & \multirow{2}{*}{ Average Sway Length } & ICC & 0.78 & 0.74 & 0.70 & 0.80 & 0.70 & 0.75 \\
\hline & & $95 \% \mathrm{CI}$ & $0.1-0.97$ & $0.3-0.95$ & $0.24-0.93$ & $0.3-0.97$ & $0.29-0.93$ & $0.32-0.95$ \\
\hline
\end{tabular}


International Journal of Biomedical Engineering and Science (IJBES), Vol. 3, No. 1, January 2016

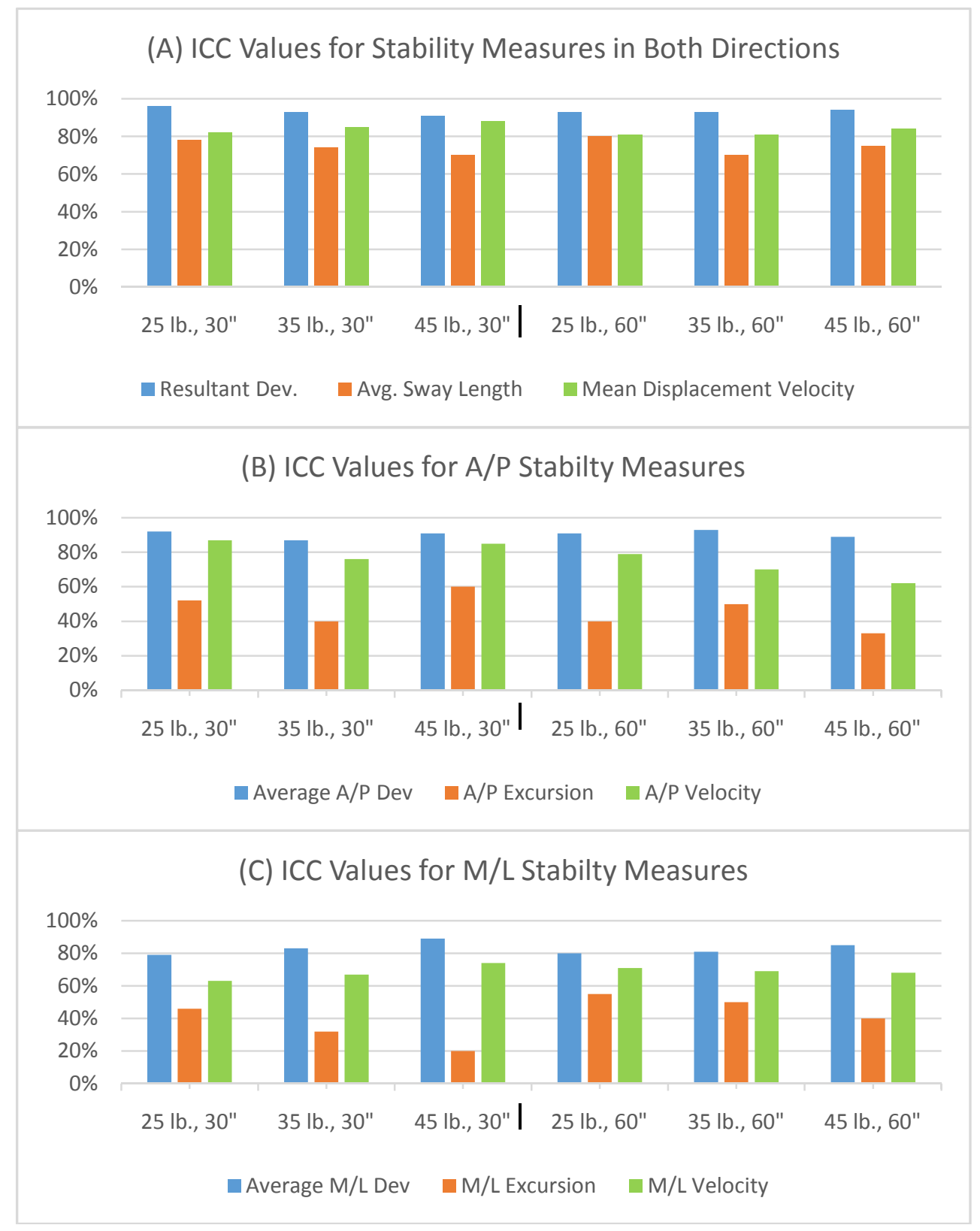

Figure 4. Comparison between stability measures in terms of ICC values. The proposed measures (blue bars) showed higher ICC values than the existing measures (orange and green bars). (A) Stability measures in both directions, (B) A/P stability measures, (C) M/L stability measures. 
International Journal of Biomedical Engineering and Science (IJBES), Vol. 3, No. 1, January 2016

\section{DISCUSSION}

The movement of the CoM is the variable that actually causes the sway of the whole body, and its components in each direction are the components of interest in studying stability. Several measures are commonly used in stability research, such as the excursion of CoM, the displacement velocity in each direction, average sway length, and the mean displacement velocity. Nevertheless, to our knowledge none of these measuresevaluate stability in relation to a reference point where the optimal stability concentrates. Therefore, the aim of this paper is to define and introduce three new stability measures that evaluate sway based on the ideal spot of stability, which is the center of base of support (CBoS). Namely, deviation of CoM from $\mathrm{CBoS}$ in the $\mathrm{A} / \mathrm{P}, \mathrm{M} / \mathrm{L}$, and resultantdeviation of $\mathrm{CoM}$ from the $\mathrm{CBoS}$ in the $\mathrm{A} / \mathrm{P}$, and $\mathrm{M} / \mathrm{L}$ together. Moreover, a lifting experiment was conducted in order to compare the new measures with other stability measures in terms of reliability. The experiment consisted of two factors each with multiple levels. The factors were the height of the shelf and the weight of the box that will be placed on the shelf. Each participant carried a box with different weights and place it on a shelf with different heights. During carrying and placing the load, stability was calculated. To our knowledge, none of the previous researchhave studied the effect of task related factor on stability (i.e. measuring stability while the subject is standing and performing tasks such as lifting and placing a weight). Several stability measures were studied in this paper, and a significant effect on one or any measure implies that the stability is affected [15]. The measures that were selected were commonly used in stability research. Moreover, it was expected that lifting a load will decrease stability, and working at a lower level that force the subject to change body posture will increase sway.

The height of the working surface had significant effect on all stability measures that have been investigated. It is obvious from Figures $6-8$, the lower the working surface, the more effect will be on body stability. This result was consistent with other studies, because when a person is squatting while carrying a load (i.e. placing a load on 30" shelf height) most of the leg muscles are under high stress [20].Moreover, DiDomenico [10] concluded that bent at waist, squatting, and kneeling were reported to produce threat to stability among construction workers. Additionally, Lin [28] studied the effects of lumbar extensor stress, and surface inclination on postural control during erect standing. The results showed that stress of lumbar extensor highly affected postural stability.

Weight lifting affected most of the stability measures significantly. Although the A/P velocity measure was not affected. This insignificant was believed because the difference between the weights is not large (i.e. $10 \mathrm{lb}$.between each level). From the Tukey's post-hoc analysis, there was a significant difference between the $25 \mathrm{lb}$. and $45 \mathrm{lb}$. weights. Clearly, the more the weight being lifted, the more effect will be on stability. These results were consistent with previous research. According to Rugelj [29] who studied the effect of increasing load on postural sway in two types of carrying: backpack and waist jacket. The conclusion was that the sway measures of the backpack group linearly increased with additional load. Moreover, Zultowski [30] studied the effect that load magnitude, and load location have on postural sway in standing while wearing a backpack, single strapped bag, briefcase, or purse. It was concluded that an increase in load magnitude produced an increase in postural sway. 
International Journal of Biomedical Engineering and Science (IJBES), Vol. 3, No. 1, January 2016
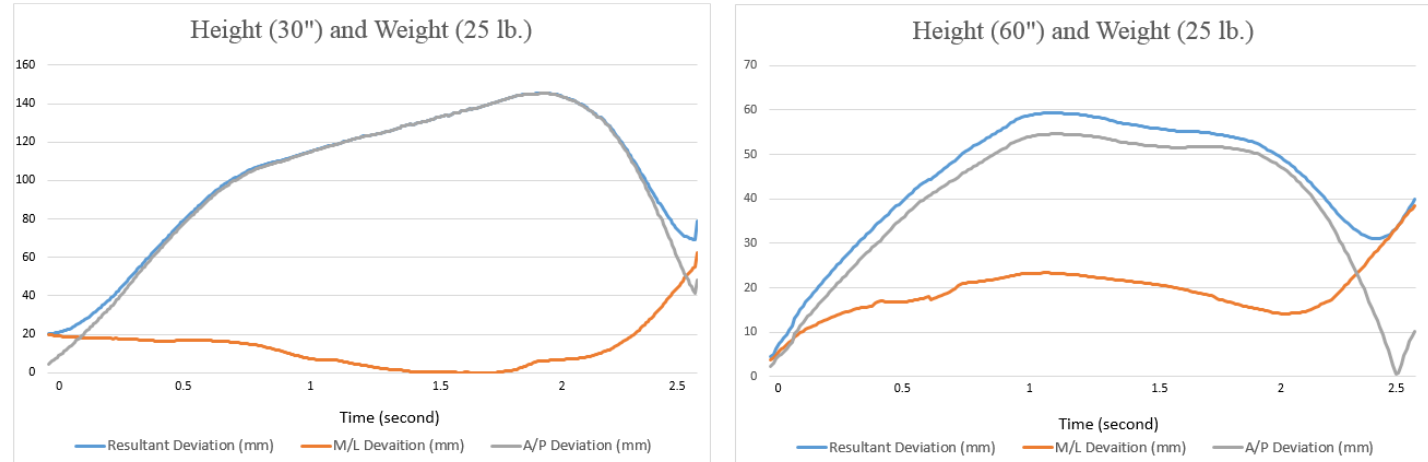

Figure.5. Effect of carrying $25 \mathrm{lb}$. on the proposed measures. It is obvious that the lower the working surface, the lower the stability.
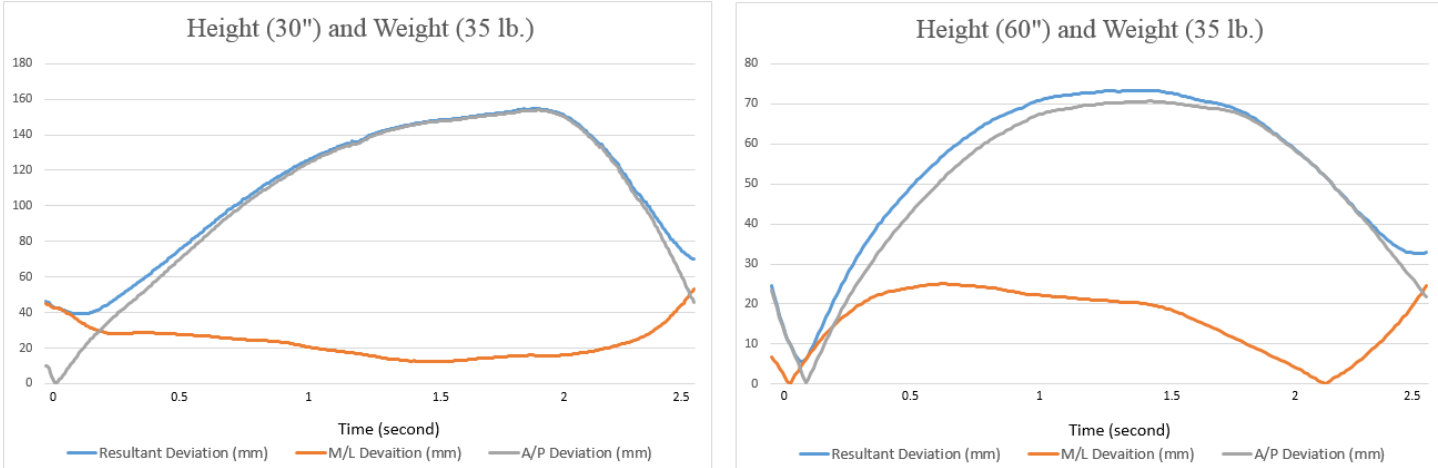

Figure.6. Effect of carrying $35 \mathrm{lb}$. on the proposed measures.
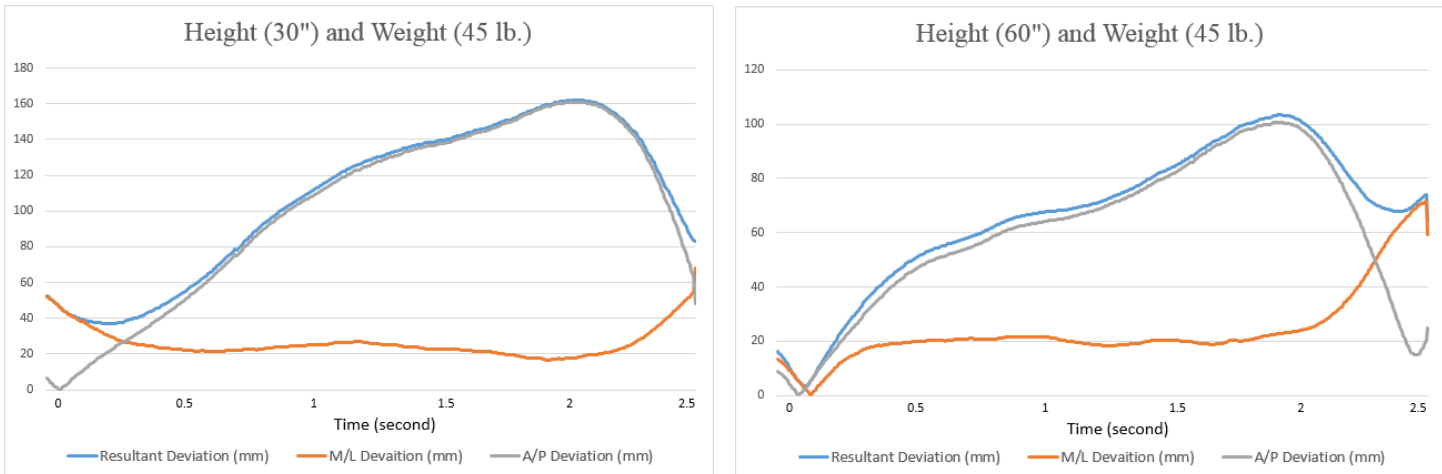

Figure.7. Effect of carrying $45 \mathrm{lb}$. on the proposed measures.It is obvious that the heavier loads have a significant effect on body stability. 
The ICC values of the proposed measures are a clear indication of their superior reliability over the existing stability measures. The reliability of the other measures (i.e. ICC value) was similar to that reported in the literature. According to Raymakers [13] who compared several stability measures. Each subject stood on a firm or a foam surface with eyes opened or closed. They found that the mean displacement velocity produced the smallest reproducibility error, followed by M/L excursion, and followed by A/P direction which had the largest intra-individual standardized coefficient of variation. In addition, Nejc [31] studied the sensitivity of individual stability measure to different stance position which were used to investigate the effect of change the size and the shape of BoS, and found that A/P, and M/L excursion had the weakest ICC (i.e. least reliability), while sway length had the strongest ICC. Nonetheless, none of the velocity measures were included in his study. Likewise, Lofand [32] who studied the reliability of stability measures on elderly healthy people, found that the displacement velocity in each direction were more reliable than the excursions in each direction. Lin [33] examined the reliability of postural sway measures on age-related differences. They found that the resultant mean displacement velocity shows more reliability than the mean distance traveled. Swanenberg [34] found that the mean velocities in each direction showed more reliability than the excursions, when they measured postural balance under two conditions: standing quiet, and standing quiet and performing simple cognitive tasks (i.e. counting backwards). Moghadam [35] determined the reliability of stability measures while the subjects were performing single and dual-task conditions and different levels of postural difficulty (i.e. rigid surface-eyes open, rigid surface-eyes closed, foam surface-eyes open, foam surface-eyes closed). They found that the mean displacement velocity was the most reliable measure among the others.

\section{CONCLUSION}

In this paper new measures for evaluating stability were introduced. They measure stability by determining how much $\mathrm{CoM}$ deviates from $\mathrm{CBoS}$. A lifting experiment was conducted, in order to test and compare the proposed with the existing stability measures. The high ICC values of the proposed stability measures, as compared to the existing stability measures, are a clear indication of their superior reliability.

Theresults of this paper provided a valuable tool for different fields, such asbiomechanists who seek measuring stability more accurately in their research. In addition, the new measures will provide powerful tool for physicians in evaluating body stability for patients who suffer from static and dynamic stabilitydifficulties. Additionally, ergonomists have new tools in evaluating stability more precisely to design tools and task that provide maximum safety and comfort for the workers.

Future research should investigate the effect of diseases that force the CoM to deviate from the optimal stability point, such as Hemiparesis, and leg length discrepancy. Hemiparesis is weakness of entire left or right side of the body. Stroke is the major cause of this disease, which defect the motor control that involve, impaired force regulation, muscle weakness, sensory deficits, and loss of range of motion [36]. Hemiparesis patients try to put more weight on the strongest side of their body, in order to maintain balance. Moreover, Future research should investigate measuring dynamic stability (i.e. while the subject is walking) instead of static stability, because most of the fall incidents occur while the person is walking. Furthermore, future research should evaluate stability while the subject is performing different tasks in different body postures, such as squatting, kneeling, and stooping. Additionally, body stability should be assessed while the workers are using different tools and equipment that they use in their job. 
International Journal of Biomedical Engineering and Science (IJBES), Vol. 3, No. 1, January 2016

\section{Conflict of Interest}

No potential conflict of interest relevant to this article was reported.

\section{ACKNOWLEDGMENT}

The authors would like to thank the Biomechanics Research Group at the University of Miami for funding this study.

\section{APPENDIX}

\subsection{VBA STABILITy CODE}

A custom Visual Basic Application (VBA) code was developed in order to calculate the proposed measures. First, the user will enter the coordinates of the BoS that were captured from the motion capturing system. Second, the user will input the height of the feet markers from the ground. This will assure that the code will eliminate any marker that leaves the ground, and deform the BoS. Then, the program will calculate the $\mathrm{CBoS}$ at each frame. Then, the user will enter the coordinates of the CoM that were recorded from the motion capturing system. After clicking "OK", the code will calculate all the proposed measures. Moreover, a chart will be drawn that let the user observe how the CoM deviated from the CBoS instantaneously. The CoM deviation will be presented as video. Another chart will show how the measures were altered in a specific period of time, as shown below. The code is available upon request.
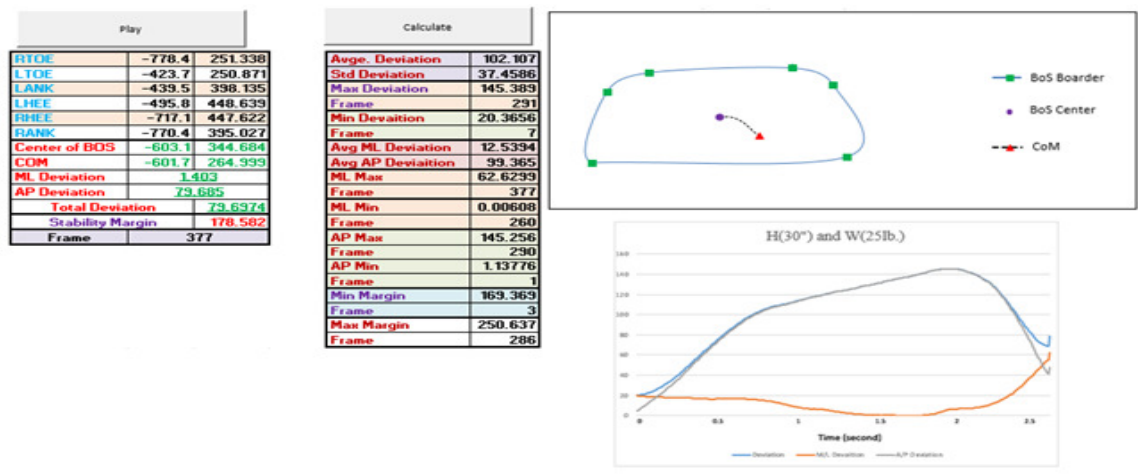

Figure.8. The outputs of VBA stability code.

\subsection{Calculating CBoS}

The most important point in the developed code is to find the center of base of support ( $\mathrm{CBoS})$. The code is capable of calculating the $\mathrm{CBoS}$ at each frame. The reflective markers of the feet (or BoS) will create a convex polygon, which all its interior angles are less than $180^{\circ}$. The code will divide the n-sided polygon into a set of (n-2) triangles for which the area and centroid will be calculated. The area of each triangle will be calculated by Heron's formula, as seen below

Area $=\sqrt{S(S-a)(S-b)(S-c)}$ 
Where, $S=\frac{a+b+c}{2}$ and

$\mathrm{a}, \mathrm{b}$, and $\mathrm{c}$ are the triangles sides

After calculating the area of each triangle, the code will find the center of each one by the following formulas.

$x_{c e n}=\frac{x_{1}+x_{2}+x_{3}}{3}$
$y_{c e n}=\frac{y_{1}+y_{2}+y_{3}}{3}$

Where, $\left[x_{1}, y_{1}\right],\left[x_{2}, y_{2}\right]$, and $\left[x_{3}, y_{3}\right]$ areatrianlecorners

Then, in order to find the center of a polygon (which is a set of triangles) the code will use the following formulas

$x=\frac{\sum\left(x_{\text {cen }_{i}} * \text { Area }_{i}\right)}{\sum \text { Area }_{i}}$

$y=\frac{\sum\left(y_{\text {cen }_{i}} * \text { Area }_{i}\right)}{\sum \text { Area }_{i}}$

\section{REFERENCES}

[1] Bureau Of Labor Statistics: Us Department Of Labor, (2013). National Census Of Fatal Occupational Injuries In 2013.

[2] Hsiao H, Simeonov P. Preventing Falls From Roofs: A Critical Review. Ergonomics. 2001; $44: 537$ 561.

[3] Holbein Ma, Redfern Ms, Postural Stability While Holding Loads In Various Postures, Proceedings Of Human Factors And Ergonomics Society 37th Annual Meetings. 1993; 676 -700.

[4] SchiffmanJm, BenselCk, Hasselquist L, GregorczykKn, Piscitelle L. Effects Of Carried Weight On Random Motion And Traditional Measures Of Postural Sway. Applied Ergonomics. 2006;37:607 614.

[5] Davis Pr, Human Factors Contributing To Slips, Trips, And Falls, Ergonomics. 1983;25:51 - 59.

[6] Holbein Ma, RedfernMs. Postural Stability While Walking And Carrying Loads In Various Postures. Proceedings Of The Human Factors And Ergonomics Society 38th Annual Meeting 1994; 564 - 567.

[7] Suruda A, Fosbroke D, Bradee R, Fatal Work-Related Falls From Roofs, Journal Of Safety Research. 1995;26:1 - 8.

[8] Parsons Tj, PizatellaTj, Collins Jw. Safety Analysis Of High Risk Injury Categories Within The Roofing Industry, Professional Safety. 1986;31:13 - 17.

[9] Didomenico A, McgorryRw, Banks Jj. Effects Of Common Working Postures On Balance Control During The Stabilisation Phase Of Transitioning To Standing. Ergonomics. 2011;54:1053 - 1059.

[10] Didomenico A, McgorryRw, Huang Y, Blair Mf. Perceptions Of Postural Stability After Transitioning To Standing Among Construction Workers. Safety Science. 2010;48:166 - 172.

[11] Duarte M, Freitas Sm. Revision Of Posturography Based On Force Plate For Balance Evaluation.RevistaBrasileria De Fisioterapia. 2010;14:183 - 193.

[12] Blaszczyk, J.W., Lowe, D.L., Hansen, P.D., Ranges Of Postural Stabilityand Their Changes In The Elderly. Gait \& Posture.1994;2:1: 11-17.

[13] RaymakersJa, Samson Mm, VerhaarHj. The Assessment Of Body Sway And The Choice Of The Stability Parameter(S). Gait\& Posture. 2005;21:48 - 58.

[14] Liu J, Zhang X, Lockhart T. Fall Risk Assessments Based On Postural And Dynamic Stability Using Inertial Measurement Unit.Safety And Health At Work. 2012;3:192-198. 
International Journal of Biomedical Engineering and Science (IJBES), Vol. 3, No. 1, January 2016

[15] Bhattacharya A, Succop P, Kincl P, Lu L, Bagc M. Postural Stability During Task Performance On Elevated And/ Or Inclined Surfaces. Occupational Ergonomics. 2003;3:83 - 97.

[16] Wade C, Garner Jc, Redfern Ms, Andres Bo, Roche J. Impact Of Extended Durations To Ballast And Postural Stability. Proceedings Of The Human Factors And Ergonomics Society 55th Annual Meeting. 2012;1047 - 1051.

[17] Simeonov, P., Hsiao, H., Dotson, B., \&Ammons, D..Control And Perception Of Balance At Elevated And Sloped Surfaces. Human Factors. 2003;45:136-147.

[18] Baloh, R.W., Jacobson K.M., Enrietto J.A., Corona S., Honrubia V., Balance Disorders In Older Persons; Quantification With Posturography. Otolaryngology - Head And Neck Surgery. 1998;119: 89-92.

[19] Whiting W, Rugg S. Dynatomy. Champaign, Il: Human Kinetics; 2006.

[20] Stambolian D, Eltoukhy M, Asfour S, Bonin S. Investigation Of Avionics Box Precision Placement Using Motion Capturing And Thermal Imaging Techniques. International Journal Of Scientific \& Engineering Research. 2011;2:1 -6.

[21] Lafond, D., Duarte, M., \&Princs, F. Comparison Of Three Methods To Estimate The Center Of Mass During Balance Assessment.Journal Of Biomechanics. 2004;37:1421-1426.

[22] De Vet, H. C., Terwee, C. B., Knol, D. L., \&Bouter, L. M.When To Use Agreement Versus Reliability Measures.Journal Of Clinical Epidemiology. 2006;59:1033-1039.

[23] Fernie, G. R., Gryfe, C. I., Holliday, P. J., \& Llewellyn, A. The Relationship Of Postural Sway In Standing To The Incidence Of Falls In Geriatric Subjects. Age And Ageing. 1982;11:11-16.

[24] Maki, B. E., Holliday, P. J., \& Topper, A. K. A Prospective Study Of Postural Balance And Risk Of Falling In An Ambulatory And Independent Elderly Population. Journal Of Gerontology: Medical Sciences. 1994;49:M72-M84.

[25] Bartlett Jw, Frost C. Reliability, Repeatability And Reproducibility: Analysis Of Measurement Errors In Continuous Variables. Ultrasound In Obstetrics \&Gynecology. 2008;31:466 - 475.

[26] Bruton A, Conway Jh, Holgate St. Reliability: What Is It, And How Is It Measured? Physiotherapy. 2000;86:94-9.

[27] Pinsault N, Vuillerme N. Test-Retest Reliability Of Centre Of Foot Pressure Measures To Assess Postural Control During Unperturbed Stance. Medical Engineering \& Physics. 2009;31(2):276-286.

[28] Lin D, Nussbaum Ma. Effects Of Lumbar Extensor Fatigue And Surface Inclination On Postural During Quiet Stance. Applied Ergonomics. 2012;43:1008 - 1015.

[29] Rugelj D. The Effect Of Load Mass And Its Placement On Postural Sway. Applied Ergonomics.2011;2:860 - 866.

[30] Zultowski I, Aruin A. Carrying Loads And Postural Sway In Standing: The Effect Of Load Placement And Magnitude. Work. 2008;30:359 - 368.

[31] Nejc S, Jernej R, Loefler S, Kern H. Sensitivity Of Body Sway Parameters During Quiet Standing To Manipulation Of Support Surface Size. Journal Of Sport Science And Medicine. 2010;9:431-438.

[32] Lafond D, Corriveau H, Hebert R, Prince F. Intrasession Reliability Of Center Of Pressure Measures Of Postural Steadiness In Healthy Elderly People. Archives Of Physical Medicine And Rehabilitation. 2004;85(6):896-901.

[33] Lin D, Seol H, Nussbaum Ma, Madigan Ml. Reliability Of Cop-Based Postural Sway Measures And Age-Related Differences. Gait \& Posture. 2008;28:337-342.

[34] Swanenburg J, Bruin Ed, Kathrin Favero K, Uebelhart D, Mulder T.The Reliability Of Postural Balance Measures In Single And Dual Tasking In Elderly Fallers And Non-Fallers.Bmc Musculoskeletal Disorders. 2008; 9:162.

[35] Moghadam, M., Ashayeri, H., Salavati, M., Sarafzadeh, J., Taghipoor, K. D., Saeedi, A., \&Salehi, R. Reliability Of Center Of Pressure Measures Of Postural Stability In Healthy Older Adults: Effects Of Postural Task Difficulty And Cognitive Load. Gait \& Posture. 2011;33(4):651-655.

[36] Aruin As, Hanke T, Chaudhuri G, Harvey R, Rao N., CompelledWeightbearing In Persons With Hemiparesis Following Stroke: The Effect Of A Lift Insert And Goal-Directed Balance Exercise. Journal Of Rehabilitation Research And Development.2000;37: 65-72. 
International Journal of Biomedical Engineering and Science (IJBES), Vol. 3, No. 1, January 2016

\section{AUTHORS BIOGRAPHY}

Mohammed Alamoudireceived his Bachelor's degree in Industrial Engineering from the College of Engineering, King Abdulaziz University, Saudi Arabia. In 2013, he received his Master's degree in Industrial Engineering from the College of Engineering, University of Miami, USA. Currently, he is pursuing his Ph.D degree in Industrial Engineering focusing his research on Ergonomics and Biomechanics at the University of Miami’s Biomechanics Laboratory.

Damon Stambolianis working on a $\mathrm{PhD}$ in Industrial Engineering focusing his research on Biomechanics at the University of Miami's Biomechanics Laboratory. Damon is also currently working in the KSC Engineering and Technology Directorate at Kennedy Space Center. Prior to working in the Engineering and Technology Directorate, Damon worked in; the Constellation Ground Operations Project office, the Space Station Program within the Orbiter Space Plane Project at KSC, and the Space Shuttle Program at KSC. Within these Programs, Damon was involved with industrial engineering, human factors, systems engineering, and lessons learned related process improvements for ground processing operations, for assembly, maintenance, inspectionofflight hardware.

ShihabAsfouris currently the Associate Dean of the College of Engineering at the University of Miami. In addition, he has been serving as the Chairman of the Department of Industrial Engineering at the University of Miami since 1999. Additionally, he holds the position of Professor in both the Biomedical Engineering and the Orthopedics and Rehabilitation Departments. Dr. Asfour received his Ph.D. in Industrial Engineering from Texas Tech University, Lubbock, Texas. He has published over 250 articles in national and international journals, proceedings and books. Dr. Asfour has served as a consultant to industrial, service, and educational organizations for over 40 years. Dr. Asfour received the Fellow Award of the Institute of Industrial Engineers in 2004. In 2002, Dr. Asfour has been awarded the Johnson A. Edosomwan Researcher of the Year, College of Engineering, University of Miami. Dr. Asfour was inducted in the Academy of Industrial Engineering at Texas Tech University in 1999. Dr. Asfour received the M MAyoub Award from the Institute of Industrial Engineers in 1998. Dr. Asfour is also the Director of the University of Miami Industrial Assessment Center, which has been funded by the Department of Energy from 20002016. 